\title{
Supply chain risk assessment of the Iranian mining industry by using fuzzy inference system
}

\author{
Amir Ahadi Oroumieh*
}

Production \& Operation Management, Pardis branch, Tehran University, Tehran, Iran

\begin{tabular}{l}
\hline C H R O N I C L E \\
\hline Article history: \\
Received December 18, 2014 \\
Accepted March 102015 \\
Available online \\
March 152015 \\
\hline Keywords: \\
Mining industry \\
Fuzzy inference system \\
Risk assessment \\
Supply chain risk management
\end{tabular}

\section{Introduction}

Emerging economies around the world are continuing to industrialize and grow, rapidly (Akabzaa, 2000). In turn this growth is driving unprecedented demand for mining commodities along with rising commodity prices (Filer, 1998). With the current global boom in mining commodities, mining firms are under pressure to meet production targets and deliver new capital projects on-schedule. Capital project investment for the world's top 40 mining companies doubled between 2010 and 2011, which has led to increased competition for scarce personnel, equipment, and materials (Halalat \& Bolourchi, 1994; Kitula, 2006).

In today's turbulent business climate, ever increasing supply risks threaten the ability of mining corporations to meet market expectations, consistently. Given rising commodity prices, the opportunity cost of lost production caused by supply issues is substantial. Failure to meet production and capital project targets can substantially influence on shareholder value, and can cause companies to lose the confidence of key partners, suppliers, and other critical stakeholders in the short term. In the long term, failure to meet production and capital targets can threaten the viability of a mining company.

\footnotetext{
* Corresponding author

E-mail address: ahadi.ffcco@gmail.com (A. Ahadi Oroumieh)

(c) 2015 Growing Science Ltd. All rights reserved.

doi: 10.5267/j.uscm.2015.3.003
} 
Supply risk is also on the rise, driven by geopolitical and economic uncertainty, the increasingly globalized nature of supply chains, and imbalances between supply and demand. There are a number of supply risks that threaten a mining company's ability to obtain reliable and secure supplies of personnel, equipment, and materials. The nature of these risks can be classified into: financial; regulatory; operational; and geopolitical. Mining companies who fail to address these risks effectively face greater risk exposure and are more likely to be impacted by supply disruptions.

Mining corporations today face challenges on several fronts when it comes to addressing supply risk effectively. There are people challenges, which include high turnover rates, a limited supply of skilled labor and service providers, and the logistics around getting personnel to mining sites in remote locations. There are process challenges throughout the mining supply chain that include: limited negotiating power in sourcing and procurement; coordination of complex global distribution networks across multiple regions and modes; a lack of upstream information necessary to perform adequate planning and forecasting; and ineffective processes to assess and quantify the magnitude of various risk types. Finally, there are technology challenges related to poor quality of data and a lack of effective analytical tools to support the modelling and evaluation of risk (Makweba \& Ndonde, 1996).

Leading practices in supply risk management address risk quantitatively and strategically, and take an integrated view of risk across the value chain and the enterprise. Strategic risks need to be segmented and separated from financial and operational risks in the current environment. Identifying the key drivers of change can help organizations prepare for changes across various time durations. Core supply chain and supply management capabilities must include an organization, with the appropriate skills and abilities, charged with managing and reducing overall supply risk. In addition, core supply chain processes in the areas of forecasting and planning, inventory management, strategic sourcing, contract management, and supplier relationship management are a basic first line of defense to combat supply risk. Those organizations who are more advanced in addressing supply risk deploy specialized risk management capabilities to address the more complex threats posed by regulatory and geopolitical shifts. These advanced capabilities include: concentrating on market intelligence by partnering with strategic suppliers to share and evaluate data on market and economic conditions; enhancing internal systems to capture data that supports dynamic decision making; and intelligent risk modelling tools to conduct scenario analysis and optimize supply decisions (Moody \& Panos, 1997).

Overall, mining companies today are faced with pressure to meet rising demand for mining commodities in a climate where the cost of supply disruptions is greater than ever. Mining companies that effectively develop the capability to manage supply risk will be better positioned to meet market demand and exceed stakeholder expectations amid volatility and uncertainty.

Mining plays a key role in the economy of Iran. The country is one of the most important mineral producers in the world, ranked among 15 major mineral-rich countries, holding some 68 types of minerals, 37 billion tons of proven reserves and more than 57 billion tons of potential reserves worth $\$ 770$ billion in 2014. Mineral production contributes only 0.6 per cent to the country’s GDP. Add other mining-related industries and this figure increases to just four per cent (2005). Many factors have contributed to this, namely lack of suitable infrastructure, legal barriers, exploration difficulties, and government control over all resources (Noronha, 2001).

The most important mines in Iran include coal, metallic minerals, sand and gravel, chemical minerals and salt. Khorasan has the most operating mines in Iran. Other large deposits which mostly remain underdeveloped are zinc (world's largest), copper (world's ninth largest reserves in 2011, according to the managing director of National Iranian Copper Industries Company), iron (world's 12th largest in 2013 according to the US Geological Survey), uranium (world's tenth largest) and lead (world's eleventh largest). Iran with roughly $1 \%$ of the world's population holds more than $7 \%$ of the world's total mineral reserves. 
Researchers have proposed several qualitative and quantitative techniques for analyzing risks such as Leontief-based models (Haimes \& Jiang, 2001), Markov chains (Asavathiratham et al., 2001) hierarchical holographic modeling (HHM) (Ezell et al., 2000; Haimes, 2004), preliminary hazard analysis (PHA) (Fullwood \& Hall, 1988), hazard and operability study (HAZOP) (Sutton, 1992), and failure mode and effects analysis (FMEA) (Yuan, 1985; Pinna et al., 2008). These methods are often used to understand what would happen based on the likelihood and consequences of a mistake.

In order to evaluate the risk of mining industry, it is necessary to accurately model and quantify the problem under consideration. On the other hand, with regard to high efficiency of fuzzy set on modeling uncertainty, we employed fuzzy set in order to model the risk of mining industry in Iran.

The main purpose of this paper is to present a new methodology based on the supply risk assessment and fuzzy inference system to provide a structured framework to build a safer and resilient projects in order to manage the unwanted events.

\section{Fuzzy risk}

Fuzzy set theory provides a simple way to reason with vague, ambiguous, and imprecise input or knowledge (Kahraman, 2008). Unlike crisp (or ordinary) sets, fuzzy sets have no sharp or precise boundaries (Aydin, 2004, Lashgari et al., 2011; Alidoosti et al., 2012; Yazdani-Chamzini \&Yakhchali, 2012; Lashgari et al., 2012; Fouladgar et al., 2012a,b,c). In crisp logic, every statement is true or false; i.e., it has a truth value 1 or 0 . In contrast, fuzzy sets have more flexible membership requirements that allow for partial membership in a set. Everything is a matter of degree, and exact reasoning is viewed as a limiting case of approximate reasoning (Kahraman, 2008). The ability of fuzzy set theory to deal effectively with the uncertainties encompassing vagueness and fuzziness, and variables that are defined linguistically or qualitatively (Fleming et al., 2007) caused this method by different researchers be used. Markowski and Mannan (2009) used Fuzzy logic for piping risk assessment and explored the application of the fuzzy logic for risk assessment of major hazards connected with transportation of flammable substances in long pipelines. As a basis for risk assessment, the framework of the fuzzy Layer of Protection Analysis (fLOPA) was used. fLOPA presents a new approach to risk assessment based on two assumptions: (1) different effects of the layer of protection functions on particular elements of the risks (frequency and severity of consequence), and (2) the application of fuzzy logic system (FLS) composed of three elements: fuzzification, inference process and defuzzification.

Elsayed (2009) developed Fuzzy inference system for the risk assessment of liquefied natural gas carriers during loading/offloading at terminals. Zhao et al. (2006) used fuzzy for risk assessment of the network security. Their applied method combined AHP method and fuzzy logical method. Davidson et al. (2006) proposed fuzzy risk assessment tool for microbial hazards in food systems. Chen (2001) presented a new algorithm to evaluate the rate of aggregative risk in software development using fuzzy set theory under the fuzzy group decision making environment. Zeng et al. (2007) developed an application of a fuzzy based decision making methodology to construction project risk assessment. They stated the application of fuzzy reasoning techniques provides an effective tool to handle the uncertainties and subjectivities arising in the construction process.

\section{Fuzzy inference system}

Fuzzy inference is the process of formulating the mapping from a given input to an output using fuzzy logic (see Fig. 1). There are various types of inference system. Mamdani-type inference and Sugenotype systems have most application. Mamdani-type inference expects the output membership functions to be fuzzy sets. After the aggregation process, there is a fuzzy set for each output variable that needs defuzzification. In general, Sugeno-type systems can be used to model any inference system in which 
the output membership functions are either linear or constant (www.mathworks.com). The following steps are necessary for successful application of modeling through a general fuzzy system:

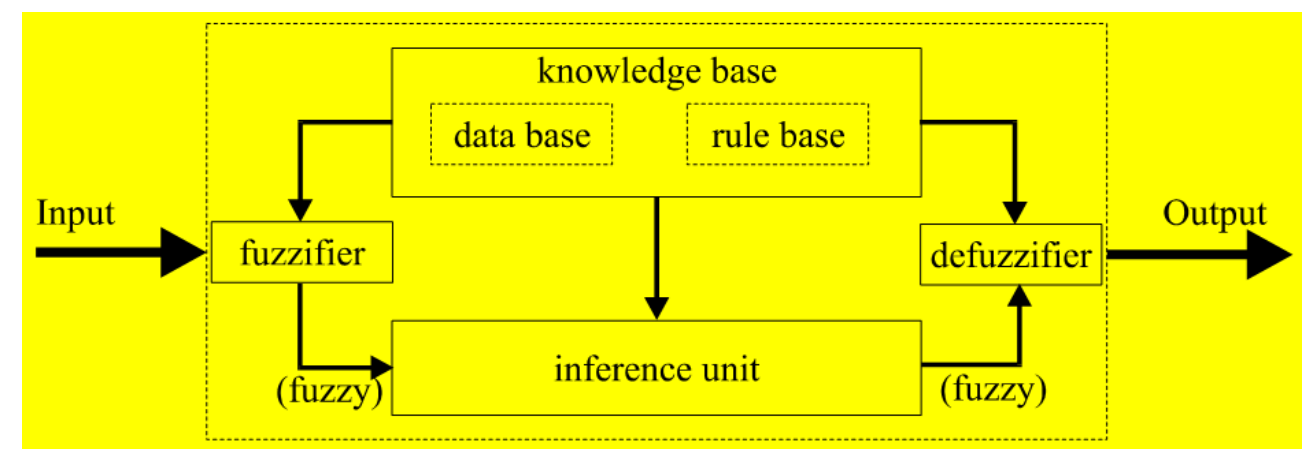

Fig. 1. Structure of fuzzy system

\subsection{Fuzzify inputs}

The first step is to take the inputs and determine the degree to which they belong to each of the appropriate fuzzy sets via membership functions. The inputs are always a crisp numerical value limited to the universe of discourse of the input variable. Fuzzification of the input and output variables carry out by considering appropriate linguistic subsets such as high, medium, low, heavy, light, hot, warm, big, small.

\subsection{Construction of rules base}

Construction of rules based on expert knowledge and/or the basis of available literature. The rules relate the combined linguistic subsets of input variables to the convenient linguistic output subset (Ross, 1995). Any fuzzy rule includes statements of “IF . . . THEN. . ." with two parts. The first part that starts with IF and ends before the THEN is referred to as the predicate (premise, antecedent) which combines in a harmonious manner the subsets of input variables. Consequent part comes after "THEN" which includes the convenient fuzzy subset of the output based on the premise part. This implies that there is a set of rules which is valid for a specific portion of the inputs variation domain. The input subsets within the premise part are combined most often with the logical "and" conjunction whereas the rules are combined with logical "or".

\subsection{Apply Implication Method}

The implication part of a fuzzy system is defined as the shaping of the consequent part based on the premise (antecedent) part and the inputs are fuzzy subsets.

\subsection{Aggregate All Outputs}

Because decisions are based on the testing of all of the rules in a FIS, the rules must be combined in some manner in order to make a decision. Aggregation is the process by which the fuzzy sets that represent the outputs of each rule are combined into a single fuzzy set. Aggregation only occurs once for each output variable, just prior to the fifth and final step, defuzzification (www.mathworks.com). The input of the aggregation process is the list of truncated output functions returned by the implication process for each rule. The output of the aggregation process is one fuzzy set for each output variable.

\subsection{Defuzzify}

Defuzzification is one of the most important subjects in fuzzy math. The result appears as a fuzzy subset and therefore, it is necessary to defuzzify the output for obtaining a crisp value that would be 
required by the administrators or engineers. Perhaps the most popular defuzzification method is the centroid calculation, which returns the center of area under the curve. There are five built-in methods supported (www.mathworks.com): centroid, bisector, middle of maximum (the average of the maximum value of the output set), largest of maximum, and smallest of maximum.

\section{Fuzzy inference system design}

In here, by experts' opinion, structure of fuzzy inference system is established. Expert judgments are normally the primary sources of information in typical engineering risk analysis methods, and can be collected through more or less formalized methods (interviews, surveys, workshops etc.) (Holmgren, 2007). Based on experts' opinion, four risky agents based on supply chain framework are selected as affective factors. In the following part, these factors are illustrated.

\subsection{Financial risk}

The uncertainty and volatility surrounding the current global economic environment has not made life any easier when it comes to managing financial risk in the supply chain. The financial risks relevant to supply in mining can be viewed as three components:

Supplier financial risk, Input price volatility risk, and Exchange rate and supply scarcity risk.

\subsection{Regulatory risk}

The mining industry is highly regulated and mines are increasingly operating in locations where local regulations and laws are continuously evolving (e.g. India, Mongolia, and Australia). The geographic placement of operating sites means they can be governed by a range of regulations related to the environment, health, and safety, all of which can impact supply decisions. In turn, these decisions can restrict and constrain the supply of goods and services to mining sites.

\subsection{Operational risk}

Obtaining secure and reliable sources of supply for a mining site is fraught with operational challenges throughout the supply chain. The most critical parts need to be on hand at all times as the opportunity cost of any downtime is high. In many cases, mines have limited supply choices for critical or proprietary parts. Among suppliers where there are wider alternatives, mines are increasingly forced to look at second or third choice vendors because their preferred supplier cannot meet current demand. Such sourcing decisions are accompanied by greater supply risk as these suppliers may be less viable, less reliable, and could potentially be lower performers. The ability to understand and evaluate a supplier's ability to meet customer needs across a range of dimensions (e.g. capacity, quality, safety, efficiency) is vital to detecting and mitigating supply risks before there is an actual impact. In the context of global demand, a strategic view is needed to balance the discussion of second and third supplier choices. Transportation across the mining supply chain can also be complex and contain risk. Transporting the supply of both products and labor to a mining site often involves several modes with many handoffs.

\subsection{Geopolitical risk}

Supply lines can often extend across a number of sovereign lines. As a result, actually getting supplies from the source to the mining site can require a journey that crosses multiple jurisdictions each with different regulations and approaches to doing business. These various political environments can in turn drive changes in regulatory conditions, potentially altering the level of supply risk to mine. 
The inputs and output are divided into five different fuzzy linguistic sets as very Low (VL), Low (L), Medium (M), High (H), and Very High (VH). Membership function of the environmental risk is shown as a sample in Fig. 2. With regard to Fig. 2, fuzzy numbers, in this paper, are Gaussian fuzzy number. It is chosen because the Gaussian kernel function exhibits properties that are mathematically and computationally tractable (Masters, 1993, 1995). The Gaussian kernel function is also a continuously differentiable function, and has the advantage of being smooth and nonzero at all points (Xie, 2003). Because of its smoothness and concise notation, the Gaussian membership function is a popular method for specifying fuzzy sets (Jang, 2005). Besides, past experiences have indicated that it is a suitable choice in many applications, and has been a reliable performer (Masters, 1993, 1995). The Gaussian membership function can be represented by (see Fig. 3):

$\operatorname{Gaussion}(x ; c, \sigma)=\mathrm{e}^{-\frac{1}{2}\left(\frac{\mathrm{x}-\mathrm{c}}{\sigma}\right)^{2}}$

where $\mathrm{c}$ and $\sigma$ are center and width of the membership function, respectively. For each input, $c$ is fixed to " 1 " for the first linguistic term; "10" for the last linguistic term and for others the center of each term. Parameter $\sigma$ is tuned so that every membership function has approximately 50 percent overlapping (orthogonal condition) (Jang et al., 1997; Lin \& Lee, 1995).This will eliminate the risk of introducing a "hole" in the input domain (Jang et al., 1997). The inputs of environmental, ecological, and socioeconomic risks are the interval between 1 and 5 .

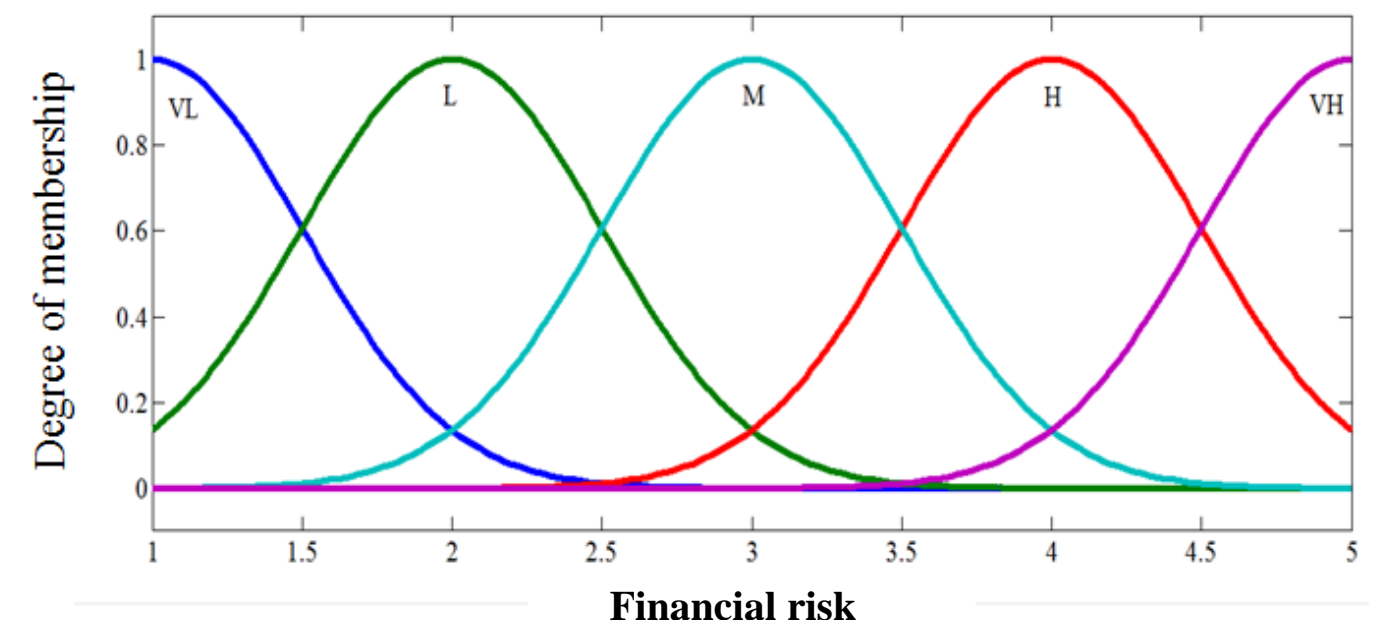

Fig. 2. Membership function of financial risk

This example is built on 625 rules, and each of the rules depends on resolving the inputs into a number of different fuzzy linguistic sets. Before the rules can be evaluated, the inputs must be fuzzified according to each of these linguistic sets. After the inputs are fuzzified, the degree to which each part of the antecedent is satisfied for each rule. If the antecedent of a given rule has more than one part, the fuzzy operator is applied to obtain one number that represents the result of the antecedent for that rule. This number is then applied to the output function. The input to the fuzzy operator is two or more membership values from fuzzified input variables. The output is a single truth value.

Before applying the implication method, we must determine the rule's weight. Every rule has a weight (a number between 0 and 1), which is applied to the number given by the antecedent. Generally, this weight is 1 (as it is for this example) and thus has no effect at all on the implication process. After proper weighting has been assigned to each rule, the implication method is implemented. The consequent is reshaped using a function associated with the antecedent (a single number). The input for the implication process is a single number given by the antecedent, and the output is a fuzzy set. Implication is implemented for each rule. Two built-in methods are supported, and they are the same 
functions that are used by the AND method: $\min$ (minimum), which truncates the output fuzzy set, and prod (product), which scales the output fuzzy set.

As long as the aggregation method is commutative (which it always should be), then the order in which the rules are executed is unimportant.

The input for the defuzzification process is a fuzzy set (the aggregate output fuzzy set) and the output is a single number. As much as fuzziness helps the rule evaluation during the intermediate steps, the final desired output for each variable is generally a single number. Defuzzification procedure is frequently achieved through centroid method as applied in this paper.

$$
F D=\frac{\sum \mu \cdot D}{\sum \mu}=\frac{\mu_{U} \cdot D_{U}+\mu_{L H} \cdot D_{L H}+\cdots}{\mu_{U}+\mu_{L H}+\cdots}
$$

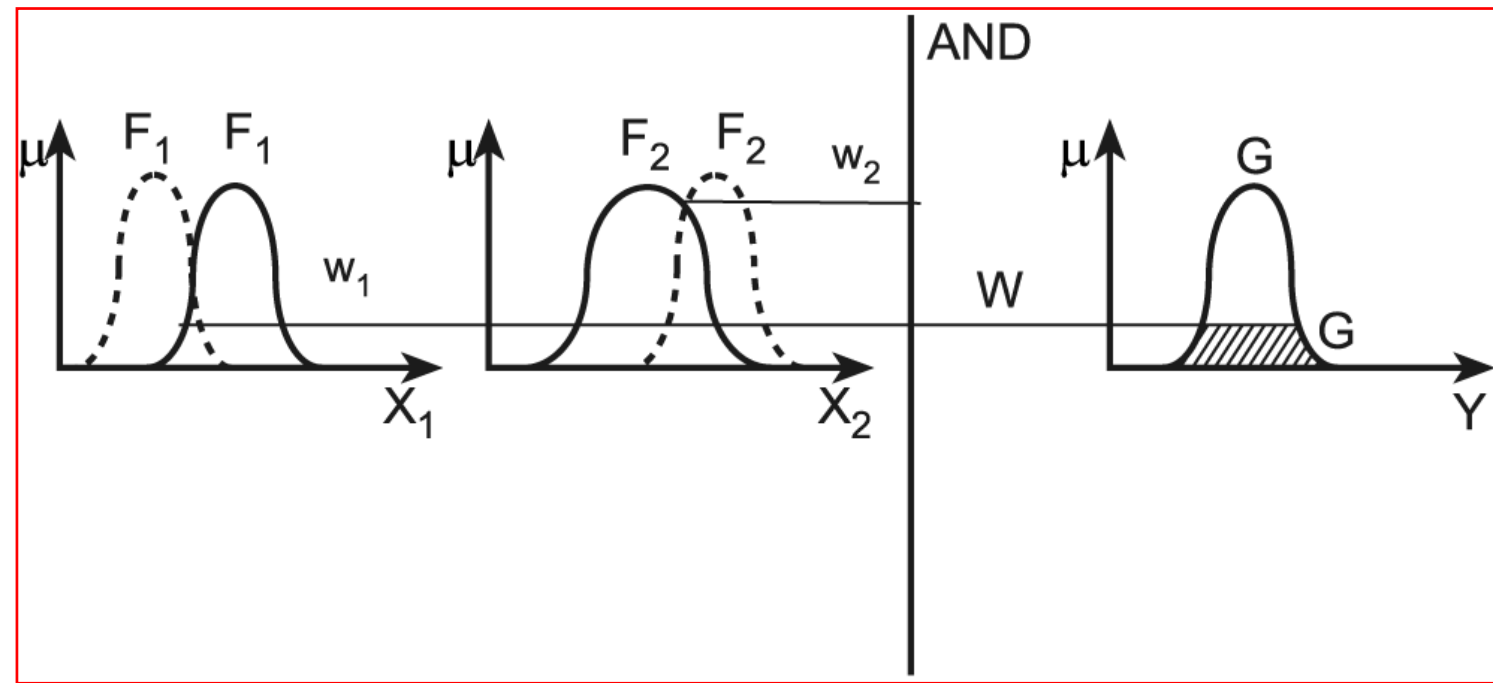

Fig. 3. Gaussian membership function

Sensitive analysis related to risk with regard to alterations of financial and operational factors is shown in Fig. 4. As in Fig. 4 indicates when financial and operational risks ascend; as a result, risk increases.

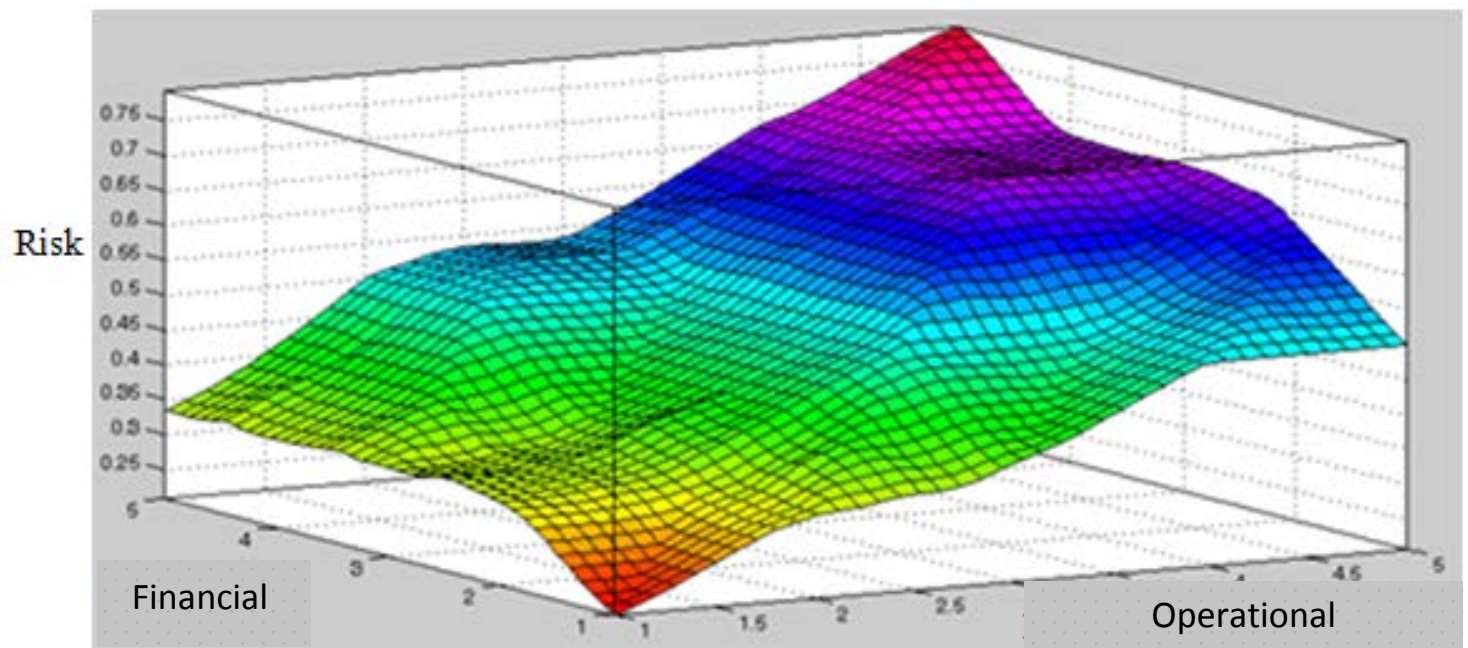

Fig. 4. The Effects of financial and Operational parameters on risk 


\section{Case study}

In this section, we provide an example to demonstrate the potential applications of the proposed model. Mining industry plays a significant role in Iran's economy; so that, this industry includes five percent in the country's GDP. The country is known as one of the most important mineral producers in the world, ranked among 15 major mineral rich countries. This industry comprises more than $7 \%$ of the world's total mineral reserves. The country holds some 68 types of minerals, 37 billion tons of proven reserves and more than 57 billion tons of potential reserves (Fouladgar et al., 2011).

In this paper, the riskiest parameters involved in the process of supply chain management, including Financial (F), Regulatory (R), Operational (O), and Geopolitical (G) are evaluated to be ranked in a descending order. To doing so, an assessor team consisting of six experts with high degree of knowledge in the field of risk analysis prioritizes risks in terms of the three parameters, so that; high risk factor can be connected with top priorities. Due to the difficulty in precisely assessing the risk factors and their relative importance weights, team members agree to evaluate risks by linguistic terms and then outputs are compared with traditional outputs. A comparison of the results using the proposed model with the conventional one is presented in Table 1. A disadvantage of the traditional method is that different sets of Financial (F), Regulatory (R), Operational (O), and Geopolitical (G) parameters may generate an identical value of risk; however, the risk implication may not necessarily be the same. For example, two cases A1 and A8 have values of 3, 1, 5, 1 and 1, 3, 5, 1 for F, R, O, and G, respectively. Both these assets will have a risk value of 10; however, the risk implications of these two cases may be completely various. This could impose a waste of resources and time. The other disadvantage of the traditional risk ranking method is that it does not take into account the relative importance among parameters. This may not be accurate in real world problems. Therefore, the outputs of fuzzy model are more adapted with real word problems. This may result in a more precise, accurate and sure risk analysis for protection.

\section{Table 1}

The comparison of supply chain risk assessment results

\begin{tabular}{|c|c|c|c|c|c|c|c|c|c|c|c|c|}
\hline \multirow{3}{*}{$\begin{array}{c}\text { Mining } \\
\text { cases }\end{array}$} & & \multicolumn{7}{|c|}{ Input } & \multicolumn{4}{|c|}{ Output } \\
\hline & & \multicolumn{3}{|c|}{ Crisp } & \multicolumn{4}{|c|}{ Fuzzy } & \multirow{2}{*}{$\begin{array}{c}\text { Traditional } \\
\text { model }\end{array}$} & \multirow[b]{2}{*}{ Rank } & \multirow{2}{*}{$\begin{array}{l}\text { Fuzzy } \\
\text { model }\end{array}$} & \multirow[b]{2}{*}{ Rank } \\
\hline & $\mathrm{F}$ & $\mathrm{R}$ & $\mathrm{O}$ & $G$ & $\bar{F}$ & $\mathrm{R}$ & $\mathrm{O}$ & $G$ & & & & \\
\hline A1 & 3 & 1 & 5 & 1 & 3.18 & 1.23 & 1.07 & 1.1 & 10 & 2 & 3.14 & 7 \\
\hline A2 & 2 & 2 & 4 & 1 & 2.02 & 2.43 & 1.92 & 1.12 & 9 & 3 & 2.93 & 5 \\
\hline A3 & 4 & 3 & 1 & 2 & 3.77 & 3.14 & 1.16 & 1.87 & 10 & 2 & 3.31 & 10 \\
\hline A4 & 1 & 2 & 5 & 2 & 1.24 & 2.21 & 4.67 & 1.76 & 9 & 3 & 2.78 & 3 \\
\hline A5 & 3 & 2 & 4 & 3 & 2.75 & 2.13 & 3.79 & 2.89 & 12 & 1 & 3.04 & 6 \\
\hline A6 & 3 & 2 & 2 & 3 & 2.69 & 2.14 & 2.21 & 3.04 & 10 & 2 & 2.34 & 1 \\
\hline A7 & 2 & 2 & 4 & 2 & 1.97 & 2.09 & 3.88 & 2.11 & 10 & 2 & 3.25 & 8 \\
\hline A8 & 1 & 3 & 5 & 1 & 2.95 & 2.84 & 4.07 & 1.21 & 10 & 2 & 3.27 & 9 \\
\hline A9 & 2 & 2 & 4 & 2 & 2.13 & 2.06 & 3.92 & 1.77 & 10 & 2 & 2.84 & 4 \\
\hline A10 & 2 & 3 & 2 & 1 & 1.78 & 3.12 & 1.93 & 1.08 & 8 & 4 & 2.67 & 2 \\
\hline
\end{tabular}

\section{Conclusion}

Mining projects play strategic role of a dynamic economy in each country; so that, governments always search solutions for reducing or preventing risks related to supply chain management. There are a variety of methods for evaluating risk. Fuzzy set is one of the most popular methods in this field because this method take into account uncertainty in the process of modeling. In this paper, fuzzy set has been employed in order to evaluate and classify the supply chain risk of mining cases. The results of this research demonstrate the proposed fuzzy model has high potential for formulating the supply chain risks involved in the mining cases. 


\section{References}

Akabzaa, T. M. (2000). Boom and dislocation. The environmental and social impacts of mining in the Wassa West District of Ghana. Accra: Third World Network-Africa.

Alidoosti, A., Yazdani, M., Fouladgar, M. M., \& Basiri, M. H. (2012). Risk assessment of critical asset using fuzzy inference system. Risk Management,14(1), 77-91.

Asavathiratham, S., Lesieutre, B., \& Verghese, G., (2001). The inuence model. IEEE Control Systems, 21(6), pp. 52-64.

Aydin, A. (2004). Fuzzy set approaches to classification of rock masses. Engineering Geology, 74(3), 227-245.

Chen, S. M. (2001). Fuzzy group decision making for evaluating the rate of aggregative risk in software development. Fuzzy Sets and Systems, 118(1), 75-88.

Davidson, V. J., Ryks, J., \& Fazil, A. (2006). Fuzzy risk assessment tool for microbial hazards in food systems. Fuzzy Sets and Systems, 157(9), 1201-1210.

Elsayed, T. (2009). Fuzzy inference system for the risk assessment of liquefied natural gas carriers during loading/offloading at terminals. Applied Ocean Research, 31(3), 179-185.

Ezell, B. C., Farr, J. V., \& Wiese, I. (2000). Infrastructure risk analysis model.Journal of Infrastructure Systems, 6(3), 114-117.

Filer, C. (1998). Mining in the South Pacific. $<$ http://www.antenna.nl/ecsiep/bulletin.html $>$.

Fleming, G., Van der Merwe, M., \& McFerren, G. (2007). Fuzzy expert systems and GIS for cholera health risk prediction in southern Africa.Environmental Modelling \& Software, 22(4), 442-448.

Fouladgar, M. M., Yazdani-Chamzini, A., \& Zavadskas, E. K. (2012). Risk evaluation of tunneling projects. Archives of civil and mechanical engineering,12(1), 1-12.

Fouladgar, M. M., Yazdani-Chamzini, A., Zavadskas, E. K., Yakhchali, S.H., Ghasempourabadi, M. H. (2012a). Project Portfolio Selection Using Fuzzy AHP and VIKOR Techniques. Transformations in Business \&Economics, 11(25), 213-231.

Fouladgar, M. M., Yazdani-Chamzini, A., \& Zavadskas, E. K. (2011). An integrated model for prioritizing strategies of the iranian mining sector: Irano kasybos sektoriaus strategiju prioriteto nustatymo integruotas modelis. Technological and Economic Development of Economy, 17(3), 459483.

Fouladgar, M. M., Yazdani-Chamzini, A., Zavadskas, E. K., \& Haji Moini, S. H. (2012). A new hybrid model for evaluating the working strategies: case study of construction company. Technological and Economic Development of Economy,18(1), 164-188.

Fullwood, R.R., \& Hall, R.E. (1988). Probabilistic risk assessment in the nuclear power industry. $1^{\text {st }}$ Ed. Pergamon Press.

Haimes, Y. Y., \& Jiang, P. (2001). Leontief-based model of risk in complex interconnected infrastructures. Journal of Infrastructure systems, 7(1), 1-12.

Haimes, Y. Y. (2005). Risk modeling, assessment, and management (Vol. 40). John Wiley \& Sons.

Halalat, H., \& Bolourchi, M.H. (1994). Geology of Iran: phosphate. Geological Survey of Iran, Tehran, $360 \mathrm{p}$.

Holmgren, A. J. (2007). A framework for vulnerability assessment of electric power systems. In Critical Infrastructure (pp. 31-55). Springer Berlin Heidelberg.

Jang, J.S.R. (2005). Fuzzy Logic Tool Box. MathWorks.

Jang, J.S.R., Sun, C.T. and Mizutani, E. (1997). Neural-Fuzzy and soft Computing. Prentice-Hall, Englewood Cliffs, NJ.

Kahraman, C. (2008). Multi-criteria decision making methods and fuzzy sets. InFuzzy Multi-Criteria Decision Making (pp. 1-18). Springer US.

Kitula, A. G. N. (2006). The environmental and socio-economic impacts of mining on local livelihoods in Tanzania: A case study of Geita District. Journal of cleaner production, 14(3), 405-414.

Lashgari, A., Fouladgar, M. M., Yazdani-Chamzini, A., \& Skibniewski, M. J. (2011). Using an integrated model for shaft sinking method selection. Journal of Civil Engineering and Management, 17(4), 569-580. 
Lashgari, A., Yazdani-Chamzini, A., Fouladgar, M. M., Zavadskas, E. K., Shafiee, S., \& Abbate, N. (2012). Equipment Selection Using Fuzzy Multi Criteria Decision Making Model: Key Study of Gole Gohar Iron Min. Engineering Economics, 23(2), 125-136.

Lin, C. T., Lee, C. G., Lin, C. T., \& Lin, C. T. (1996). Neural fuzzy systems: a neuro-fuzzy synergism to intelligent systems (Vol. 205). Upper Saddle River NJ: Prentice hall PTR.

Makweba, M.M, \& Ndonde, P.B. (1996). The mineral sector and the national environmental policy. In: Mwandosya MJ, et al., editors. Proceedings of the workshop on the national environmental policy for Tanzania (Dar es Salaam, Tanzania), p. 73-164.

Markowski, A. S., \& Mannan, M. S. (2009). Fuzzy logic for piping risk assessment (pfLOPA). Journal of loss prevention in the process industries,22(6), 921-927.

Masters, T. (1995). Advanced Algorithms for Neural Networks: A C ++ Sourcebook, Wiley, New York, NY.

Masters, T. (1993). Practical Neural Network Recipes in $C++$. Academic Press, San Diego, CA.

Moody, R., \& Panos, S.P. (1997). Environmental assessment of mining projects. $<$ http://www.worldbank.org/mining.xls>.

Noronha, L. (2001). Designing tools to track health and well being in mining regions of India. Natural Resource Forum, 25, 53-65.

Pinna, T., Caporali, R., \& Tesini, A. (2008). Failure Mode and Effect Analysis for remote handling transfer systems of ITER. Fusion Engineering and Design,83(10), 1710-1714.

Ross, J. T. (1995). Fuzzy logic with engineering applications. New York: McGraw-Hill Inc, p. 593.

Sutton, I.S. (1992). Process reliability and risk management. $1^{\text {st }}$ ed. Van Nostrand Reinhold.

Tauli-Corpuz, V. (1997). The globalisation of mining and its impact and challenges for women. $<$ http://www.twnside.org.sg/bookstore.htm>.

UNEP. (1997). Industry and environment, mining and sustainable development. $<$ http://www.uneptie.org/vol20no4.htm>.

UNEP. (2001). Environmental Aspects of Phosphate and Potash Mining. $<$ https://www.elaw.org/system/files/PotashMining.pdf>.

www.mathworks.com

Xie, M. (2003). Fundamentals of Robotics: Linking Perception to Action. World Scientific Publishing Co Ltd, London.

Yazdani-Chamzini, A., \& Yakhchali, S. H. (2012). Tunnel Boring Machine (TBM) selection using fuzzy multicriteria decision making methods. Tunnelling and Underground Space Technology, 30, 194-204.

Yuan, J., (1985). A strategy to establish a reliability model with dependent components through FMEA. Reliability Engineering, 11, 37- 45.

Zeng, J., Nigel, M., \& Smith, J., (2007). An Application of a fuzzy based decision making methodology to construction project risk assessment. International Journal of Project Management, 25, 589-600.

Zhao, D-M., WANG, J-H., \& MA, J. F. (2006). Fuzzy risk assessment of the network security. Proceedings of the Fifth International Conference on Machine Learning and Cybernetics, Dalian, 13-16 August 2006, 4400-4405. 